\title{
The commonalities of kidney and eye disease
}

\author{
Clyde Schultz* \\ Department of Biology, University of Calgary, Calgary, Alberta Canada
}

\begin{abstract}
The greater ocular space and the kidney as two distinct organs with vastly different functions and locations in the human body, also share many striking similarities and commonalities. While they differ in location and function, they are alike in terms of internal structure and pathogenic pathways. Further, they have similar risk factors in terms of disease progression. The object of this article is to discuss these similarities and differences.
\end{abstract}

\section{Commonality}

What may be termed chronic kidney disease (CKD) and certain eye diseases such as glaucoma, age related macular degeneration (AMD) and diabetic retinopathy (DR) share many risk factors including age, excessive weight in relation to body type, and smoking [1]. Both of which are risk factors for hypertension. In addition, both have extensive vascular networks and the retina segment and glomerular filtration barrier have closely similar pathways of development. Further, the eye and the kidney share the renin-angiostatin-aldosterone network $[2,3]$. All these conditions may lead to the development of either or both CKD and some type ocular disease. CKD is a systemic disease that is progressive in nature. Over time it alters the structure and function of the kidney, which may lead to cardiac disease. The disease process may originate with the loss of function of the nephron unit, which leads to renal failure ultimately. This invariably leads to organ failure in other parts of the body, thus the systemic nature of the disease.

Some recent studies have indicated that progressive CKD is linked to the decline of the Klotho. Should Klotho levels decline, renal disease tends to become more pronounced [4,5]. Decline in Klotho has also been linked to AMD, cataract and retinopathy. Animal studies have linked Klotho to calcification of tissue, including vascular tissue, and in the case of the ocular environment lens and retinal differentiation, but this link is somewhat less established in the ocular environment. Klotho appears to negatively influence vitamin D metabolism and phosphate metabolism.

\section{Pathological mechanisms}

Table 1 outlines the common underlying pathological mechanisms for both kidney and eye diseases. Both disease conditions have common causes and important similar risk factors.

Table 1. Outlines the common underlying pathological mechanisms for both kidney and eye diseases. Both disease conditions have common causes and important similar risk factors

\begin{tabular}{|l|c|c|}
\hline Pathology & Ocular Disease & $\begin{array}{c}\text { Kidney or renal } \\
\text { disfunction }\end{array}$ \\
\hline Inflammation & $\mathrm{X}$ & $\mathrm{X}$ \\
\hline Vascular Disfunction & $\mathrm{X}$ & $\mathrm{X}$ \\
\hline Cardiac Disease and associated risk factors & $\mathrm{X}$ & $\mathrm{X}$ \\
\hline Genetics & $\mathrm{X}$ & $\mathrm{X}$ \\
\hline Arteriosclerosis & $\mathrm{X}$ & $\mathrm{X}$ \\
\hline Klotho & $\mathrm{X}$ & $\mathrm{X}$ \\
\hline Systemic Disease & & $\mathrm{X}$ \\
\hline
\end{tabular}

\section{Glycation end products}

Advanced glycation end (AGE) products are structures formed under hyperglycemic conditions or high oxidative stress [6]. They react and act in concert with AGE receptors [7]. These receptors occur on endothelial cells of the kidney and on the human lens of the eye, especially in cataract patients. The AGE effect is one of strong (covalent) cross linking and insolubility of lens proteins. High levels of serum AGE as is the case with CKD patients can induce eye syndromes such as either cataract or in some cases retinopathy [7].

\section{Arteriosclerosis}

Chronic kidney disease may increase homocysteine and lipoprotein and increase oxidative stress [8,9]. There is a decrease in transforming growth factor beta. Modeling of AMD suggests that arteriosclerosis can have effects on eye tissues such as Bruch's membrane, and the presence of increased amounts of lipid in either the membrane or the sclera causes choriocapillary pressure, and calcification of the membrane. This is similar to both CKD and AMD.

\section{Association between chronic kidney disease and dia- betic retinopathy}

Organogenesis specific for ocular and renal functions share several genes including Pax2, BMP7 and WT-1 [3]. Ocular abnormalities due to genetic mutation give rise to issues in both the renal and ocular organ systems. The presence of retinal vascular lesions are somewhat predictive of the on-set of chronic kidney disease. Chronic kidney disease is strongly associated with macular edema, cataract and elevated IOP.

There have been reports suggesting at least a tentative relationship between CKD and DR [10]. There appear to be a common yet not completely understood pathway linking the two. Studies have shown retinopathy associated in individuals with an increased risk for kidney disease. Similar reports exist between individuals with elevated

*Correspondence to: Clyde Schultz, Department of Biology, University of Calgary, Calgary, Alberta T2N 1N4, Canada, E-mail: schultzc@ucalgary.ca

Key words: kidney, ocular, chronic, klotho

Received: February 07, 2020; Accepted: February 18, 2020; Published: February 26,2020 
intraocular pressure (IOP) and/or glaucoma. Several investigators have seen associations of kidney disease and glaucoma patients.

There seem to be stronger associations between kidney disease and ocular disease of the anterior segment of the eye $[11,12]$. Calcification of eyelid margins and the cornea have been seen in patients with advanced chronic kidney disease. This is interesting as the cornea is an avascular organ. There is good clinical evidence that central corneal thickness is associated with kidney disease due to endothelial changes in the cornea. It is postulated that increased urea concentrations in the aqueous humor was toxic to the endothelium.

\section{References}

1. Schiffrin EL, Lipman ML, Mann JFE (2007) Chronic Kidney Disease: effects on the cardiovascular system. Circulation 116: 85-97. [Crossref]

2. Wilkinson-Berka JL, Agrotis A, Deliyanti D (2012) The retinal renin-angiotensin system: roles of angiotensin II and aldosterone. Peptides 36: 142-150. [Crossref]

3. Izzedine H, Bodaghi B, Vacher VL, Deray G (2003) Eye and Kidney: from clinical findings to genetic explanation. J Am Soc Nephrol 14: 516-529. [Crossref]

4. Kuro-o M, Matsumura Y, Aizawa H, Kawaguchi H, Suga T, et al. (1997) Mutation of the mouse klotho gene leads to a syndrome resembling ageing. Nature 390: 45-51. [Crossref]
5. Fon Tacer K, Bookout AL, Ding X, Kurosu H, John GB, et al. (2010) Research resource: comprehensive expression atlas of the fibroblast growth factor system in adult mouse. Mol Endocrinol 24: 2050-2064. [Crossref]

6. Busch M, Franke S, Stein G, Wolf G (2010) Advanced glycation end-products and the kidney. Eur J Clin Invest 40: 742-755. [Crossref]

7. Nagaraj R, Linetsky M, Stitt AW (2012) The pathogenic state of Maillard reaction in the aging eye. Amino Acids 42: 1205-1220. [Crossref]

8. Bostom A, Shemin D, Lapane KL Sutherland P, Nadeau MR et. al. (1996) Hyperhomocysteinemia, hyperfibrinogenemia, and lipoprotein (a) excess in maintenance dialysis patients: a matched case-controlled study. Atherosclerosis 125: 91-101.

9. Stefoni S, Cianciolo G, Donati G, Dormi A, Silvestri MG et. al (2002) Low TGF-beta 1 serum levels are a risk factor for atherosclerosis disease in ESRD patients. Kidney Int 61: 324-335. [Crossref]

10. Penno G, Solini A, Zoppini G, Orsi E, Zerbini G, et. al (2012) Rate and determinants of association between advanced retinopathy and chronic kidney disease in patient with type 2 diabetes: The Renal Insufficiency and Cardiovascular Events (RIACE) Italian multicenter study. Diabetes Care 35: 2317-2323. [Crossref]

11. Klaassen-Brokema N, van Bijsterveld OP (1993) Limbal and corneal calcification in patients with chronic renal failure. Br J Ophthamol 77: 569-571. [Crossref]

12. Canellos H, Cooper J, Paek A, Chien J (2005) Multiple calcified deposits along the eyelid margins secondary to chronic renal failure and hyperparathyroidism. Optometry 76: 181-184. [Crossref]

Copyright: $@ 2020$ Schultz C. This is an open-access article distributed under the terms of the Creative Commons Attribution License, which permits unrestricted use, distribution, and reproduction in any medium, provided the original author and source are credited. 